\title{
Absence of Dressing versus Dressing in Gynaecological and Obstetrical Surgery at the University Hospital of Brazzaville
}

\author{
C. Itoua, Eouani Lme, P. Obara Ngoli Mbongui, P. S. Koko, L.-H. Iloki* \\ Obstetric and Gynaecology Department, Brazzaville University Hospital Centre, Brazzaville, Congo \\ Email: ^herviloki@yahoo.fr
}

How to cite this paper: Itoua, C., Lme, E., Mbongui, P.O.N., Koko, P.S. and Iloki, L.-H. (2018) Absence of Dressing versus Dressing in Gynaecological and Obstetrical Surgery at the University Hospital of Brazzaville. Open Journal of Obstetrics and Gynecology, 8, 246-252.

https://doi.org/10.4236/ojog.2018.83026

Received: January 29, 2018

Accepted: March 20, 2018

Published: March 23, 2018

Copyright $\odot 2018$ by authors and Scientific Research Publishing Inc. This work is licensed under the Creative Commons Attribution International License (CC BY 4.0).

http://creativecommons.org/licenses/by/4.0/

c. (i) Open Access

\begin{abstract}
Objective: To compare the evolution of the operative site in the presence or absence of an occlusive skin dressing. Patients and methods: Prospective, comparative study that took place at the University Hospital of Brazzaville from January 1st to August 31st, 2016. 120 patients were randomly recruited divided into two groups: A study group consisting of 60 patients without a dressing and a control group consisting of 60 patients. Results: Sociodemographic characteristics were similar in both groups, as well as pre- and intraoperative characteristics. Postoperative complications included parietal infection ( 3 vs. 4 cases, $p>0.05$ ), one case of disunion, and one case of skin irritation by the plaster in the study group. The duration of healing was shorter in the control group compared to the study group ( $11 \pm 2$ days vs. $12 \pm 2, p>$ 0.05). The average cost of care equipment was 3.5 times higher for the group with dressing (5120 FCFA vs. 18620 FCFA, $p<0.05$ ). In the study group, only one patient was afraid of seeing her wound. Patients in the control group were less satisfied, indeed they dreaded the time of removal of the plaster because of the pain.
\end{abstract}

\section{Keywords}

Absence of Dressing, Operating Site, Cicatrisation, Cost, Gynaecological and Obstetric Surgery, Congo, Brazzaville

\section{Introduction}

In gynaecological and obstetrical surgery, empirical hospital practice requires that after surgery of the abdomen, the operative site is covered by an occlusive skin dressing. A protective role against trauma and surrounding microbial flora 
is assigned to the dressing [1].

However, this practice has not been validated scientifically and would be questioned by some authors [2] [3]. They think that the dressing does not influence the evolution of the operative wound and would like it to be totally removed. It does not influence the occurrence of parietal infection and external skin scarring.

In Congo, no study has been done on this subject. Thus, a first preliminary study is carried out with the aim of contributing to the improvement of knowledge on the management of the operating site.

The objective of this work is to compare the evolution and the cost of the surgical wound in the presence or absence of an occlusive skin dressing.

Google Translate for Business: Translator Toolkit Website Translator.

\section{Patients and Methods}

This was a randomized study carried out after a favourable opinion of the ethics committee, at the CHU of Brazzaville from January 1st to August 31st, 2016. It concerned the gynaecological and obstetric interventions performed in the department and meeting the following inclusion criteria: scheduled or emergency abdominal surgery, ASA score of 1 or 2 for scheduled patients, informed consent. We did not include women who underwent laparoscopic surgery for pelvic peritonitis and pelvic abscess.

The sampling consisted of two groups by randomly matching each uncovered dressing to a covered dressing, which resulted in the formation of two groups with two separate protocols:

- Study group: The surgical wound was not covered from the operating room, after painting of the latter with a compress soaked in povidone iodine dermal. The patient was seen every 48 hours for a brushing and a follow-up of the wound until the external clinical cicatrisation.

- Control group: the operative wound was covered by an occlusive skin dressing from the operating room after suture. The occlusive skin dressing was made of compresses impregnated with povidone iodine dermic covered by plaster. It was renewed on the 4 th postoperative day and systematically every $48 \mathrm{~h}$ until the external clinical scarring.

The last control of the operative wound was performed on the 30th postoperative day.

For each patient we evaluated the general characteristics, the variables per and post-operative.

The data has been validated after evaluation and input using the Excel 2007 and SPSS software on WINDOWS version 0 .

Descriptive statistics presented qualitative variables in proportions (\%) and continuous variables in mean + standard deviation.

Statistical inference used the various parametric tests after univariate analyses.

Comparison of percentages used the Pearson Chi-square test and that of the $\mathrm{t}$-Student averages. 
The value of $p<0.05$ was considered a threshold of statistical significance.

\section{Results}

\subsection{Socio-Demographic Characteristics}

Patients with bandages had a mean age like their no-dressing counterparts $(34 \pm$ 1 years vs. $34 \pm 2$ years, NS $p>0.05$ ).

No significant difference was observed between patients with dressing and those without dressing, in terms of education, marital status and occupation ( $p>$ 0.05) (Table 1).

\subsection{Preoperative Characteristics}

No significant difference was observed between the dressing group and the dressing-less group with respect to operative indication, operator qualification, laparotomy programming, and type of anaesthesia $(p>0.05)$ (Table 2$)$.

The mean laparotomy duration was similar in both groups $(57.9 \pm 24.5 \mathrm{~min}-$ utes vs. $62.4 \pm 27$ minutes, $p>0.05$ ).

\subsection{Intraoperative Characteristics}

The type of skin incision, the nature of the cutaneous suture and the use of blood transfusion were identical between the two groups (Table 3 ).

\subsection{Post-Operative Characteristics}

Patients with occlusive skin dressings had a longer average healing time than their non-bandaged counterparts ( $12 \pm 2$ days vs. $11 \pm 2$ days, $p>0.05$ ) (Figure $1)$.

Table 1. General characteristics.

\begin{tabular}{lccc}
\hline & \multicolumn{3}{c}{ Occlusive dressing N (\%) } \\
\cline { 2 - 4 } Age & With & Without & P value \\
schooling & $59(50)$ & $34 \pm 8$ & \\
- Educated & $1(50)$ & $59(50)$ & 0,721 (NS) \\
- None-educated & & $1(50)$ & \\
& Marital status & & \\
- Single & $25(51)$ & $24(49)$ & 0,169 (NS) \\
- Married & $33(49,3)$ & $34(50,7)$ & \\
- Divorced & $1(33,3)$ & $2(66,7)$ & \\
- Widow & $0(0)$ & $1(100)$ & \\
& Profession & & \\
- Employee & $21(50)$ & $39(50)$ & \\
- Unemployed & $39(50)$ &
\end{tabular}


Table 2. Preoperative characteristics.

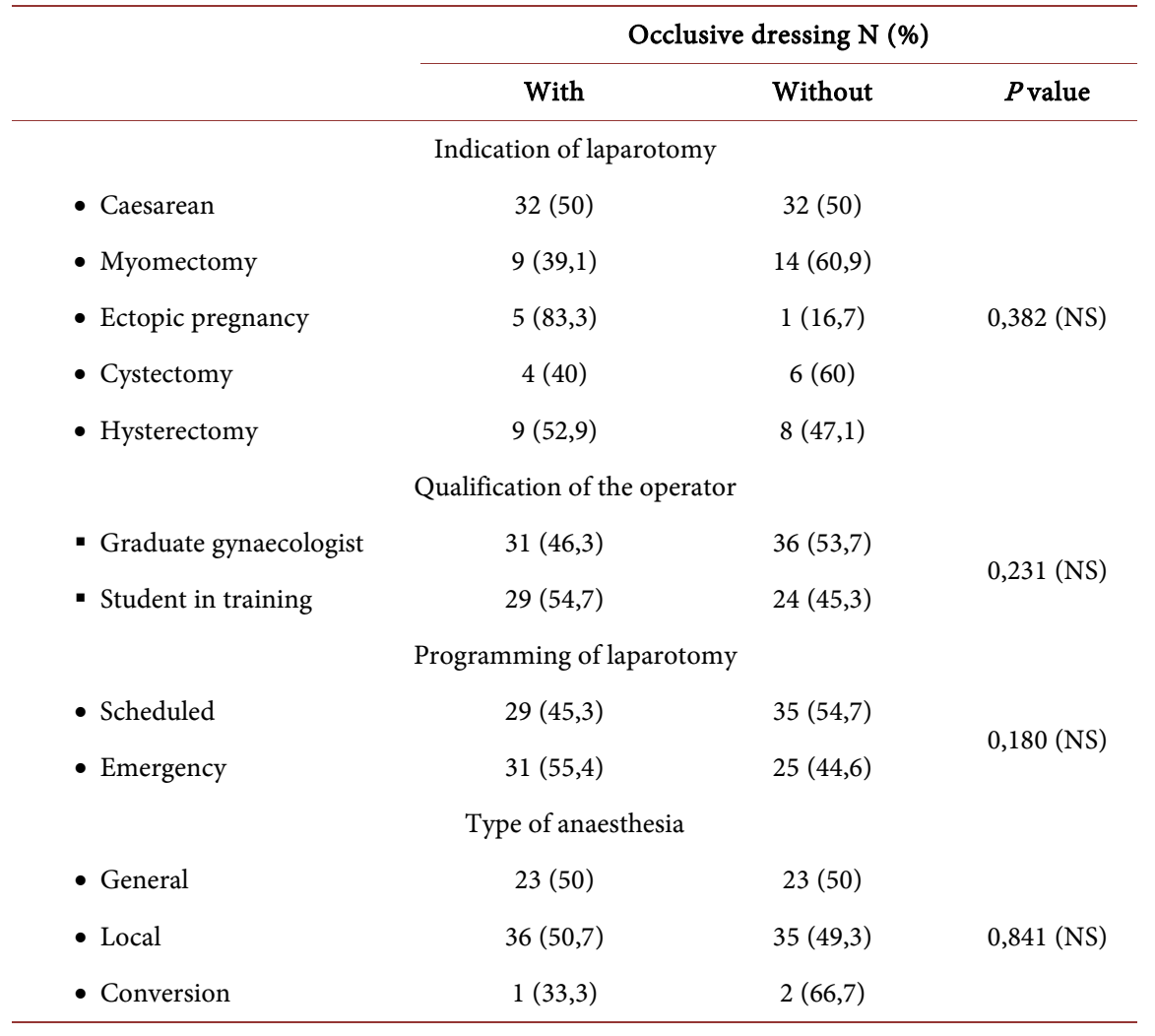

Table 3. Preoperative characteristics.

\begin{tabular}{lccc}
\hline & \multicolumn{3}{c}{ Occlusive dressing N (\%) } \\
\cline { 2 - 4 } - Transversal & Type of incision & Without & P value \\
\hline - Median under umbilical & $91(51)$ & $49(49)$ & \\
& $9(45)$ & $11(55)$ & 0,404 (NS) \\
- Mype of transversal incision & & \\
- Pfannenstiel & $16(47,1)$ & $18(52,9)$ & 0,361 (NS) \\
& $35(53)$ & $31(47)$ & \\
- Transfused & Blood transfusion & & 0,500 (NS) \\
- None-transfused & $8(47,1)$ & $9(52,9)$ & \\
& $52(50,5)$ & $51(49,5)$ & \\
- Intradermal overlock & Cutaneous suture & & 0,309 (NS) \\
- Separate points & $51(50,5)$ & $50(49,5)$ & \\
- Resorbable threads & $9(47,4)$ & $10(52,6)$ & \\
\hline
\end{tabular}

NS: non-significative. 


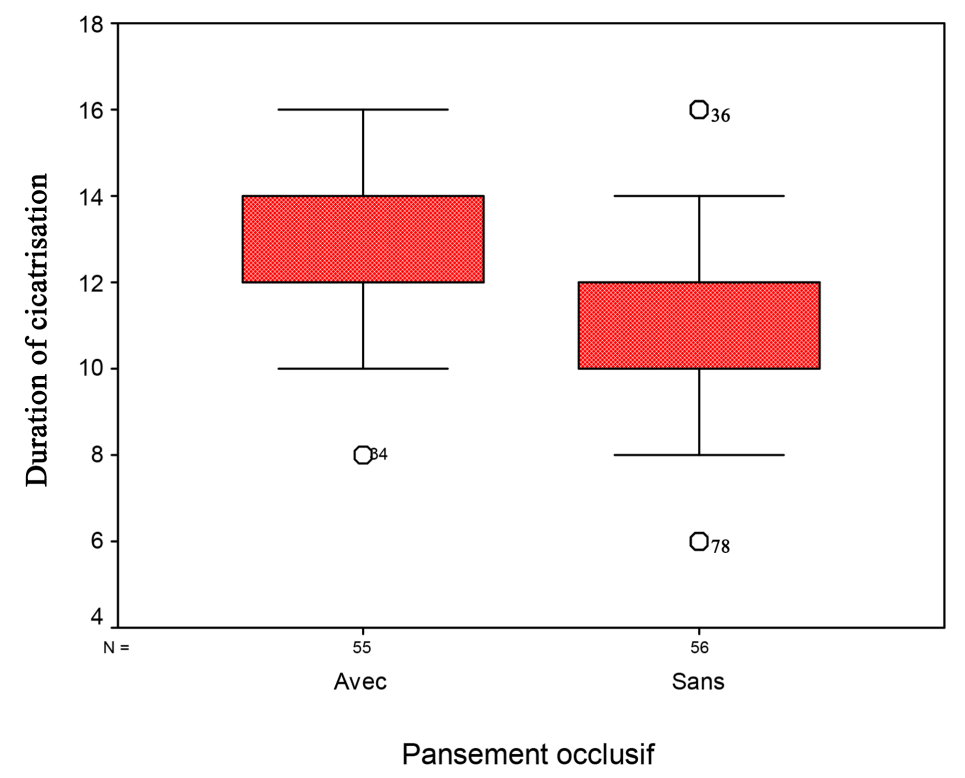

Figure 1. Duration of cicatrisation.

Five patients with bandages feared the removal of the bandage because of the pain, a patient was afraid to see her wound in the group without dressing.

Postoperative follow-up was complicated without significant difference in operative site infection in both groups. One case of skin irritation was observed with the occlusive dressing (Table 4).

When the dressing is not performed, the average cost of care is 5120 FCFA, while it is 3.5 times higher when the dressing is done, i.e. 18620 FCFA (Table 5).

\section{Discussion}

The average age of patients in our study is higher than that reported by Konan Wheat [4] in Abidjan 29.87 years and 29.58 years in the bandage group. The patients in her series were mainly women during the period of genital activity operated for caesarean section, uterine rupture and salpingectomy.

Like the African literature [4] [5], age was not a factor that could influence the quality of the surgical site healing. On the other hand, according to Skodan [6] in the West, the age of the patient is a factor that influences the incidence of infection of the operative site.

The qualification of the operator and the average duration of the operation did not influence the evolution of the postoperative course. The same observation was made by DossehEkoué [5] in Lomé. Other authors [7] [8] believe that the skill of the surgeon influences the occurrence of infection of the operative site.

Parietal infection of the operative site was observed without significant difference in both groups as in the Konan Wheat series [4]. However, the overall rate of infection of the surgical site of $13.5 \%$ is higher than ours because of the consideration of pathologies at high risk of infection such as chorioamnionitis in the series of Konan Wheat. 
Table 4. Post-operative characteristics.

\begin{tabular}{|c|c|c|c|}
\hline & \multicolumn{3}{|c|}{ Occlusive dressing $\mathrm{N}(\%)$} \\
\hline & With & Without & $P$ value \\
\hline \multicolumn{4}{|c|}{ Operative suites } \\
\hline - Simples & $55(49,5)$ & $56(50,5)$ & \multirow{2}{*}{$0,500(\mathrm{NS})$} \\
\hline - Complicated & $5(55,6)$ & $4(44,4)$ & \\
\hline$\star$ Infection & $4(57,1)$ & $3(42,9)$ & \multirow{3}{*}{0,358 (NS) } \\
\hline \&isunity & 0 & $1(100)$ & \\
\hline$\star$ Irritation & $1(100)$ & 0 & \\
\hline \multicolumn{4}{|c|}{ Blood transfusion } \\
\hline - Transfused & $3(50)$ & $3(50)$ & \multirow{2}{*}{0,660 (NS) } \\
\hline - Non-transfused & $57(50)$ & $57(50)$ & \\
\hline
\end{tabular}

Table 5. Comparison of equipment costs used in CFA francs.

\begin{tabular}{|c|c|c|c|c|c|c|}
\hline & \multicolumn{3}{|c|}{ Group with bandage } & \multicolumn{3}{|c|}{ Group without bandage } \\
\hline & Number & $\begin{array}{c}\text { Price } \\
\text { unitary }\end{array}$ & Total & Number & Price unitary & Total \\
\hline $\begin{array}{l}\text { Povidone iodine } \\
\text { dermal (125 ml) }\end{array}$ & 1 flacon & 1620 & 1620 & 1 flacon & 1620 & 1620 \\
\hline $\begin{array}{l}\text { Sterile compress } \\
(40 \mathrm{~cm} \times 40 \mathrm{~cm})\end{array}$ & 4 boxes & 1500 & 6000 & 2 boxes & 1500 & 3000 \\
\hline $\begin{array}{c}\text { Plaster } \\
(18 \mathrm{~cm} \times 10 \mathrm{~cm})\end{array}$ & 1 box & 7000 & 7000 & 0 & 0 & 0 \\
\hline Surgical gloves $7^{1 / 2}$ & 8 pairs & 500 & 4000 & 1 pair & 500 & 500 \\
\hline Grand Total & & 18,620 & & & 5120 & \\
\hline
\end{tabular}

Similarly, in Switzerland, Meylan [2] did not find a significant difference between the two groups and suggested that the dressing should therefore be totally removed.

The incidence of surgical site infections is variable, and it is often difficult to compare two series because of the involvement of multiple factors [9] [10] [11] that can intervene: the level of expertise of the hospital (Hospital Center University or not), its size, the type of surgery, the age of the patient and the ability of the surgeon.

Anyway, our different rates of infection of the operative site are significantly higher than those reported in developed countries ranging from 1.8 to $3.6 \%$ [2].

Cases of cutaneous irritation of the isolated skin were noted in the group with dressing.

The average duration of skin scarring is similar in both groups and is like that of Konan Ble [4].

Several authors [2] [4] [5] agree that dressing contributes to increased service costs. 


\section{Conclusions}

The attitude of not covering the operative site with an occlusive dressing has advantages and does not have significant scientifically documented disadvantages.

Also, we note the reduction of the healing time, the costs related to the care, the workload of the nursing staff and the sharing of the management of the follow-up of the evolution of the said operation with the patient.

Therefore, dressing of the operative site is useless and should be totally removed.

\section{References}

[1] Churchill, M.A., Turner, S.M. and Bintcliff, I.W. (1992) Controlled Prospective Trial of Wound Management in Elective Hand Surgery. Journal of the Royal College of Surgeons of Edinburgh, 37, 203-204.

[2] Méylan, G. and Tsccantz, P. (2001) Pansementou absence de pansement sur les plaiesopératoires: étude prospective et comparative. Annales de Chirurgie, 126, 459-462. https://doi.org/10.1016/S0003-3944(01)00531-4

[3] Thomeret, G. (1964) Suppression totale des pansements post opératoires. La Presse Médicale, 72, 1716.

[4] Konan Blé, R., Koman, M., Seni, K., Adjoussou, S., Quenum, G. and Koné M. (2008) Absence de pansement sur la plaie opératoire en chirurgie gynécologique et obstétricale: étude comparative avec le pansementconventionnel. Medecine d'Afrique Noire, 5512, 648-652.

[5] Dosseh Ekoué, D., Doleaglenou, A., Fortey, Y.K. and Ayite, A.E. (2008) Pansement versus absence de pansement au delà de 48 heuresen milieu tropical: essairandomisé. Journal De Chirurgie, 145, 143-146. https://doi.org/10.1016/S0021-7697(08)73724-4

[6] Skodan, S.J. and Davis, R.H. (1993) Principles of Wound Healing and Growth Factor Considerations. Journal of the American Podiatric Medical Association, 83, 223-227. https://doi.org/10.7547/87507315-83-4-223

[7] Culver, D.H., Horan, T.C., Gaynes, R.P. and National Nosocomial Infections Surveillance System (1991) Surgical Wound Infection Rates by Wound Class, Operative Procedure, and Patient Risk Index. American Journal of Medicine, 91, 152-157. https://doi.org/10.1016/0002-9343(91)90361-Z

[8] Pittet, D. and Ducel, G. (1994) Infection Risk Factors Related Operating Room. Infection Control \& Hospital Epidemiology, 15, 456-462. https://doi.org/10.2307/30148495

[9] Francioli, P., Nahimana, I. and Widmer, A. (1996) Infection du site chirurgical, revue. Swiss-Noso, 3, 1-6.

[10] Emmerson, A.M., Eustone, J.E., Griffin, M., Kelsey, M.C. and Smyth, E.T. (1996) The Second National Prevalence Survey of Infections in Hospitals, Overview of Results. Journal of Hospital Infection, 32, 175-190. https://doi.org/10.1016/S0195-6701(96)90144-9

[11] Farron, A. and Tschantz, P. (1990) Facteursprédictifs de l'infection post-opératoire. Helvetica Chirurgica Acta, 57, 909-911. 